\title{
Neutrophil elastase induces cell proliferation and migration by the release of TGF- $\alpha$, PDGF and VEGF in esophageal cell lines
}

\author{
YOSHIYUKI WADA, KAZUHIRO YOSHIDA, YASUHIRO TSUTANI, HIDEAKI SHIGEMATSU, \\ MAMORU OEDA, YUICHI SANADA, TAKAHISA SUZUKI, HIROZUMI MIZUIRI, \\ YOICHI HAMAI, KAZUAKI TANABE, KEI UKON and JUN HIHARA
}

Department of Surgical Oncology, Research Institute for Radiation Biology and Medicine, Hiroshima University, Hiroshima 734-8553, Japan

Received July 23, 2006; Accepted August 28, 2006

\begin{abstract}
Rapid regrowth or recurrent growth of occult cancer cells are often observed after esophagectomy or postoperative complications. In order to clarify the mechanism of such oncological circumstances, we focused on neutrophil elastase (NE), which degrades a broad spectrum of extracellular matrix and cell surface proteins. In the present study, we demonstrated that NE stimulated the growth of all of the five esophageal cell lines (TE-1, -7, -8, -12 and -13) by MTT assay and promoted cell invasion by cell migration assay. Protransforming growth factor- $\alpha$ (pro-TGF- $\alpha$ ) from the cell membrane was released to the culture medium as a mature form after treatment with $5 \mu \mathrm{g} / \mathrm{ml} \mathrm{NE}$, and it reached the maximum level of $153 \%$ compared to the control values at 15 min of treatment in TE-13 cells. The phosphorylation of epidermal growth factor receptor (EGFR) rapidly occurs after treatment with NE and triggered the extracellular signalregulated kinases 1 and 2 (ERK) signaling pathway. Moreover, NE induced release of platelet-derived growth factor-AA (PDGF-AA), PDGF-BB and vascular endothelial growth factor (VEGF) to $141.9,227.7$, and $171.6 \%$ of the control values,
\end{abstract}

Correspondence to: Dr Kazuhiro Yoshida, Department of Surgical Oncology, Research Institute for Radiation Biology and Medicine, Hiroshima University, 1-2-3 Kasumi, Minami-ku, Hiroshima 734-8553, Japan

E-mail: kyoshida@hiroshima-u.ac.jp

Abbreviations: NE, neutrophil elastase; TGF- $\alpha$, transforming growth factor- $\alpha$; EGFR, epidermal growth factor receptor; ERK, extracellular signal-regulated kinases; PDGF-AA, platelet-derived growth factor-AA; VEGF, vascular endothelial growth factor; ECM, extracellular matrix; ARDS, respiratory distress syndrome; SIRS, systemic inflammatory response syndrome; MTT, 3-(4,5dimethyl-2-tetrazolyl)-2,5-diphenyl-2H tetrazoluim bromide; RTPCR, realtime-polymerase chain reaction; ALI, acute lung injury; MAPK, ras-raf-mitogen-activated protein kinase

Key words: esophageal cancer, TE-13, TGF- $\alpha$, PDGF, VEGF, neutrophil elastase, sivelestat, EGFR, ERK respectively. A specific NE inhibitor, sivelestat, significantly inhibited the NE-induced cell proliferation, cell invasion and subsequently inhibited the signal transduction pathway. Furthermore, sivelestat significantly inhibited NE-induced release of TGF- $\alpha$, PDGF-AA, PDGF-BB and VEGF in the medium in TE-13 esophageal carcinoma cells. These results strongly indicate that NE released from activated neutrophils stimulates the growth and progression of esophageal cancer cells by releasing the growth factors on the cell surface and that sivelestat, a specific NE inhibitor, blocks these processes. Furthermore, we postulate that postoperative administration of sivelestat might be useful as a new molecular-targeting cancer therapy as well as for the treatment of postoperative respiratory complications.

\section{Introduction}

Esophageal cancer is one of the most common malignancies worldwide and its prognosis is extremely poor compared to other gastrointestinal cancers, because of the difficulties in early detection and treatment. The operation requires thoracotomy, laparotomy and in some cases cervical lymph node dissection, which might cause perioperative or postoperative complications including pneumonia and anastomotic leakage. Under these circumstances, we often experience systemic inflammatory response, which is caused by neutrophil elastase (NE) produced by activated polymorphonuclear neutrophils and monocytes/macrophages (1).

$\mathrm{NE}$ is a serine protease which degrades a broad spectrum of extracellular matrix (ECM) and cell surface proteins, such as elastin, interstitial collagens, proteoglycans, fibronectin, laminin, and type IV collagens (2-5). Under physiological damaged circumstances, such as presence of neoplasm, surgical stress and inflammation, the balance between elastase and antiprotease is collapsed, and the predominant elastolytic activity causes the destruction of ECM. NE also cleaves protransforming growth factor- $\alpha$ (pro-TGF- $\alpha$ ) on the surface of human airway epithelial cells by the proteolytic effect and releases mature, soluble TGF- $\alpha$ on human airway epithelial cells. Release of TGF- $\alpha$ activates the epidermal growth factor receptor (EGFR) signaling cascade (6) resulting in excretion of 
the mucinous secretion in the peripheral airways that might cause severe respiratory complication after major surgical or severe inflammatory response. A specific synthetic NE inhibitor, sivelestat, has been developed for the treatment of various inflammatory diseases. The anti-inflammatory effect of sivelestat provides good efficacy for surgical stress, and can reduce the morbidity and organ dysfunction including the acute respiratory distress syndrome (ARDS).

On the other hand, we previously demonstrated that the multiple autocrine loops play important roles in the carcinogenesis and progression of esophageal carcinomas, and that TGF- $\alpha$, epidermal growth factor (EGF) and EGFR are the key growth factor receptor systems that mediate the prominent growth signals in cancer cells.

In clinical practice, we often experience cases of rapid recurrence or regrowth of tumors after major cancer surgery including esophageal cancer operation, or cases of perioperative surgical complications with systemic inflammatory response syndrome (SIRS) that involves the release of NE from neutrophils or cancer cells, as reported by Yamashita et al (7-9). These facts provoke the idea that NE released from neutrophils may stimulate the rapid spreading of cancer cells $(10,11)$ and that a specific synthetic NE inhibitor, sivelestat, can reduce the possibility of rapid regrowth of the circulating occult cancer cells or the residual cells in the local regions.

In the present study, we demonstrated the potential activity of NE on growth stimulation and invasion of esophageal cancer cells and also clarified the important role of sivelestat on the inhibition of these processes.

\section{Materials and methods}

Chemicals. Human NE isolated from human purulent sputum was purchased from Elastin Products (Pacific, MO, USA). Sivelestat was kindly provided by Ono Pharmaceutical Co. (Tokyo, Japan). All other chemicals were of analytical grade and were purchased from Wako Pure Chemicals (Osaka, Japan).

Cell lines. TE-1, - - , -8, -12 and -13 esophageal cancer cell lines were kindly provided by the Institute of Development, Aging, and Cancer, Tohoku University (Sendai, Japan). All esophageal carcinoma cell lines were routinely grown in RPMI1640 (Nissui Co., Tokyo, Japan) supplemented with 7\% fetal bovine serum (FBS), $20 \mathrm{mM}$ HEPES (pH 7.4), $100 \mathrm{UI} / \mathrm{ml}$ penicillin, $100 \mu \mathrm{g} / \mathrm{ml}$ streptomycin, $2.0 \mathrm{mM}$ L-glutamine, and $1 \%$ non-essential amino acids in a humidified atmosphere of $5 \% \mathrm{CO}_{2}$ at $37^{\circ} \mathrm{C}$.

Cell growth assay. Cell growth was assessed by a standard 3-(4,5-dimethyl-2-tetrazolyl)-2,5-diphenyl-2H tetrazolium bromide (MTT) assay (CellTiter 96 aqueous non-radioactive MTT cell proliferation assay; Promega, Madison, WI) (12). Briefly, cells were seeded into 96-well culture plates $\left(10^{4}\right.$ cells/ well) in RPMI-1640 containing 7\% FBS. Following a 24-h incubation, the cells were incubated for $48 \mathrm{~h}$ with varied concentrations of 0.1-10 $\mu \mathrm{g} / \mathrm{ml} \mathrm{NE}$, and $1-1000 \mu \mathrm{g} / \mathrm{ml}$ sivelestat in either the absence or presence of $5 \mu \mathrm{g} / \mathrm{ml} \mathrm{NE}$. After incubation, $10 \mu 1$ of MTT (Sigma, St. Louis, MO)

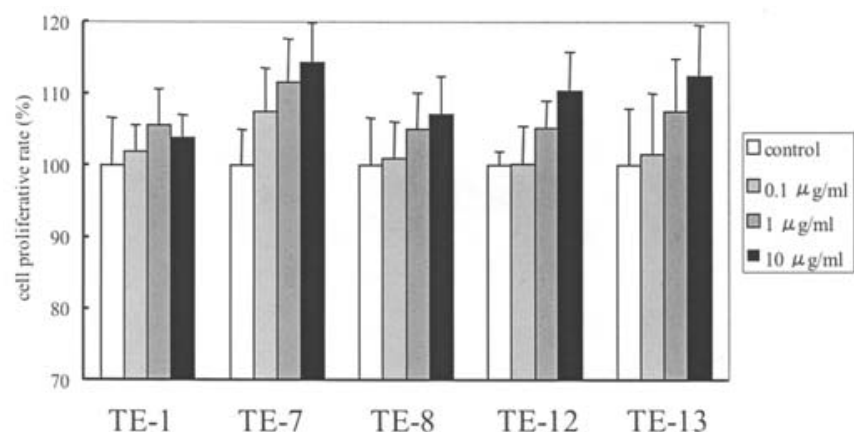

Figure 1. Proliferative effect of neutrophil elastase in esophageal cancer cells, TE-1, - 7, -8, -12 and -13, assessed by MTT assay. Clear dose-dependent growth proliferation was observed. Results are representative of three separate experiments.

solution $(5 \mathrm{mg} / \mathrm{ml})$ was added to each well and the plates were incubated for $3 \mathrm{~h}$ at $37^{\circ} \mathrm{C}$. The growth medium was then replaced with $150 \mu 1$ of dimethyl sulfoxide per well and the absorbance at 450/540 nm was measured using a Titertek multiscan.

Cell migration assay. The chemotaxis assay was done using QCM Chemotaxis 96-well cell migration assay kit according to the manufacturer's instructions. RPMI-1640 medium $(150 \mu \mathrm{l})$ with $10 \% \mathrm{FBS}$ as a chemoattractant was added to the lower chamber. Cell suspension $(100 \mu \mathrm{l})\left(10^{5} \mathrm{cells} / \mathrm{ml}\right)$ added indicated concentrations $(1-500 \mu \mathrm{g} / \mathrm{ml})$ of sivelestat alone or together with $5 \mu \mathrm{g} / \mathrm{ml}$ neutrophil elastase without chemoattractant into upper migration chamber. A membrane $(8 \mu \mathrm{m})$ was placed between the upper and lower chamber. After incubation for $24 \mathrm{~h}$ at $37^{\circ} \mathrm{C}$ in a humidified $5 \% \mathrm{CO}_{2}$ incubator, cells remaining in the upper chamber were discarded. Cells that migrated to the lower side of the filter were completely dislodged by Cell detachment solution in the wells. Dislodged cells were stained by Lysis buffer/dye solution and the absorbance at 450/540 nm was measured using a Titertek multiscan, as reported previously (13).

Isolation of RNA and semi-quantitative RT-PCR. Total RNA was isolated using the RNeasy mini kit (Qiagen, Valencia, CA) according to the manufacturer's instructions. Total RNA $(1 \mu \mathrm{g})$ was converted to cDNA using the GeneAmp RNA PCR core kit (Applied Biosystems, Foster City, CA) according to the manufacturer's instructions. PCR was performed using SYBR Premix Ex Taq (Takara Bio Inc., Shiga, Japan) for the TGF- $\alpha$ gene. Real-time detection of the emission intensity of SYBR-Green bound to double-stranded DNA was carried out using the Roche PCR thermal cycler MP. The PCR conditions for TGF- $\alpha$ amplification consisted of an initial $15 \mathrm{sec}$ denaturation at $95^{\circ} \mathrm{C}$, followed by 50 cycles of $95^{\circ} \mathrm{C}$ for $5 \mathrm{sec}$ and $60^{\circ} \mathrm{C}$ for $20 \mathrm{sec}$. The initial template concentrations were derived from the cycle number at which the fluorescent signal crossed a threshold in the exponential phase of the PCR reaction. The relative gene expression was determined by the threshold cycles (cross point) for the TGF$\alpha$ gene and for the $\beta$-actin (ACTB) gene (initial control), as described previously (14). The TGF- $\alpha$ primer sequences were 5'-AGA TTC CCA CAC ACT CAG TTC TGC TTC-3' (TGF- $\alpha-F)$ and 5'-TCA CAG GTG CAC CAA CGT A-3' 
TE-

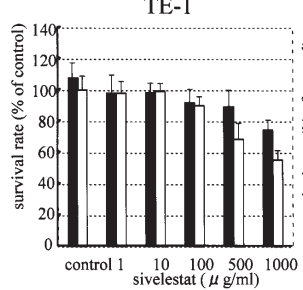

TE-12

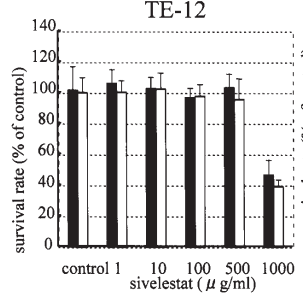

Figure 2. Growth inhibitory effects of sivelestat in five esophageal cancer cell lines, TE-1, -7, -8, -12 and -13. Cells were seeded onto 96-well plates and incubated for $24 \mathrm{~h}$, following pretreatment. The cells were incubated for $48 \mathrm{~h}$ at $37^{\circ} \mathrm{C}$ in a humidified atmosphere of $5 \% \mathrm{CO}_{2}$ with various concentrations $(1,10,100,500$ and $1000 \mu \mathrm{g} / \mathrm{ml})$ of sivelestat with $10 \mathrm{mg} / \mathrm{ml}$ $\mathrm{Na}_{2} \mathrm{CO}_{3}$ alone or together with $5 \mu \mathrm{g} / \mathrm{ml}$ neutrophil elastase. MTT assays were performed to examine the growth inhibitory effect of sivelestat. Significant growth inhibition of cells was observed at concentrations $>100 \mu \mathrm{g} /$ $\mathrm{ml}$ sivelestat.

(TGF- $\alpha-\mathrm{R})$. The ACTB primer sequences were 5'-CCA ACT GGG ACG ACA TGG AG-3' (ACTB-L) and 5'-GCA CAG CCT GGA TAG CAA CG-3' (ACTB-R).

Immunoprecipitation. Cells were seeded onto a $90 \mathrm{~mm}^{2}$ dish. When cells were confluent, they were gathered and lysed in a lysis buffer (50 mM Tris- $\mathrm{HCl}(\mathrm{pH} 8.0), 150 \mathrm{mM}$ sodium chloride, $1 \%$ Triton $\mathrm{X}-114,50 \mathrm{mM}$ sodium fluoride, $1 \mathrm{mM}$ sodium orthovanadate and compleate protease inhibitor cocktail tablets (Roche, Indianapolis, IN) and clarified by centrifugation. Supernatants were incubated with $10 \mu \mathrm{g}$ of anti-EGFR antibody (Santa Cruz Biotechnology, Santa Cruz, CA) immobilized onto protein $\mathrm{G}$ Sepharose for $2 \mathrm{~h}$ at $4^{\circ} \mathrm{C}$ with gentle rotation. Beads were washed extensively with lysis buffer and immune complexes were eluted in x2 Laemmli buffer, boiled and microcentrifuged.

Western blot analysis. In order to further examine the effects of NE and sivelestat on the phosphorylation of EGFR-signaling in TE-13 cells, Western blot analysis was performed. Cells were seeded onto a $90 \mathrm{~mm}^{2}$ dish, grown to confluence and incubated in the presence of $5 \mu \mathrm{g} / \mathrm{ml} \mathrm{NE}$ either alone or simultaneously with $100 \mu \mathrm{g} / \mathrm{ml}$ sivelestat for different periods of incubation up to $60 \mathrm{~min}$. Cells were then harvested and lysed in lysis buffer and the protein concentration of the lysates was measured. Total cell protein extracts (15 $\mu \mathrm{g} / \mathrm{lane})$ were separated by SDS-PAGE using readygels J (Bio-Rad Laboratories, Milan, Italy) and electrophoretically transferred onto PVDF membranes. The membranes were then incubated with anti-human B-actin (Sigma), EGFR, PY99, ERK1/2, and pERK1/2 (Santa Cruz) antibodies. Immunoreactive proteins were visualized by enhanced chemiluminescence (Amersham International, Buckinghamshire, UK), as reported previously (14).
Immunoassay. The concentrations of TGF- $\alpha$, platelet-derived growth factor-AA (PDGF-AA), PDGF-BB or vascular endothelial growth factor (VEGF) in the cell culture supernatant and the cell lysate obtained from TE-13 was measured using commercially available sandwich ELISA kits according to the manufacturer's instructions. The ELISA kit for TGF- $\alpha$ was purchased from Oncogene Research Products (Cambridge, MA). The ELISA kits for PDGF-AA, PDGF-BB and VEGF were purchased from R\&D Systems, Inc. (Minneapolis, MN). The kit for detecting the VEGF recognizes all the subtypes of VEGFs including VEGF-A, B, C and D. TE-13 cells were seeded onto six-well culture plates. TE-13 cells were incubated with serum-starved medium for $24 \mathrm{~h}$ and washed with PBS three times and then treated for 10 min with $5 \mu \mathrm{g} / \mathrm{ml} \mathrm{NE}$ and/ or 10 or $100 \mu \mathrm{g} / \mathrm{ml}$ sivelestat. The cell culture supernatants were harvested and the cell lysates were collected on ice with lysis buffer after cells were washed with cold PBS three times. Assays were performed using the 10-min collected supernatants and cell lysates.

Statistical analysis. Statistical analysis was performed using the Student's t-test, and $\mathrm{p}<0.05$ was considered statistically significant.

\section{Results}

Potentiation of cell proliferation by NE. The initial study was performed to clarify that NE stimulates the growths of esophageal cancer cells. Cells were incubated for $48 \mathrm{~h}$ with $0.1,1$ or $10 \mu \mathrm{g} / \mathrm{ml} \mathrm{NE}$ and the MTT assays were performed. As shown in Fig. 1, the growth of the five esophageal cancer cell lines was increased in a dose-dependent manner after treatment with NE. Growth of TE-1, -7, -8, -12 and -13 cells was stimulated to $103,114,107,110$ and $112 \%$ of control levels, respectively $(\mathrm{p}=0.09,<0.01,<0.01,<0.01$ and $<0.01$, respectively), when cells were treated with a concentration of $10 \mu \mathrm{g} / \mathrm{ml} \mathrm{NE}$. In order to confirm that this growth stimulatory effect of NE was neutralized by sivelestat, MTT assays were performed for TE-1, $-7,-8,-12$ and -13 cells treated with $5 \mu \mathrm{g} /$ $\mathrm{ml} \mathrm{NE}$ and with $1,10,100,500$ or $1000 \mu \mathrm{g} / \mathrm{ml}$ sivelestat for 48 h. As shown in Fig. 2, the growth stimulatory effect of NE was reversed with concomitant treatment with NE even at the concentration of $1-10 \mu \mathrm{g} / \mathrm{ml}$ sivelestat in TE-1, -8 and -12 . Significant growth suppression was noted when concentrations of $500-1000 \mu \mathrm{g} / \mathrm{ml}$ sivelestat were used, and suppression occurred in a dose-dependent manner. Especially, the growth of TE-13 cells treated with sivelestat at concentrations of 100,500 and $1000 \mu \mathrm{g} / \mathrm{ml}$ with NE was significantly inhibited to $81.0,50.0$ and $20.1 \%$ compared with the controls, respectively $(p<0.001)$, demonstrating that the growth stimulatory effect of NE was blocked by sivelestat and also sivelestat itself might have the potential of cancer cell growth inhibition.

Migration activity. To elucidate the possibility that NE released from activated neutrophils after surgery can stimulate the invasive potential of esophageal cancer cells, the invasion assay was performed. TE-13 cells were incubated with NE and/or sivelestat in Boyden Chamber with pores sized $8 \mu \mathrm{m}$ for $48 \mathrm{~h}$, and cells which migrated through the membrane 


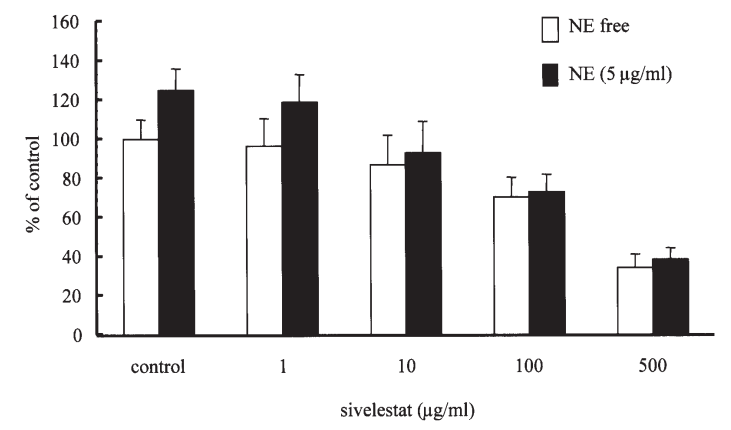

Figure 3. Cell migration inhibitory effects of sivelestat in TE-13 cells. Cells were seeded with various concentrations $(1,10,100$ and $500 \mu \mathrm{g} / \mathrm{ml})$ of sivelestat alone or together with $5 \mu \mathrm{g} / \mathrm{ml}$ neutrophil elastase into the upper migration chamber. After incubation for $24 \mathrm{~h}$ at $37^{\circ} \mathrm{C}$ in a humidified $5 \%$ $\mathrm{CO}_{2}$ incubator, cells were measured through the filter. Data are expressed as mean \pm SD of 6 wells.

\section{A. TGF- $\alpha$ (supernatant)}

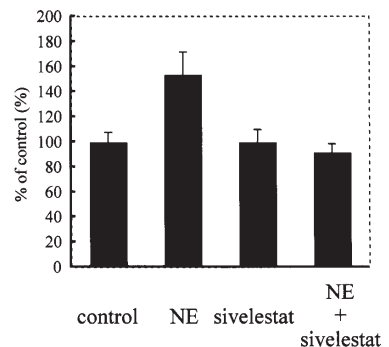

B. TGF- $\alpha$ (cell lysate)

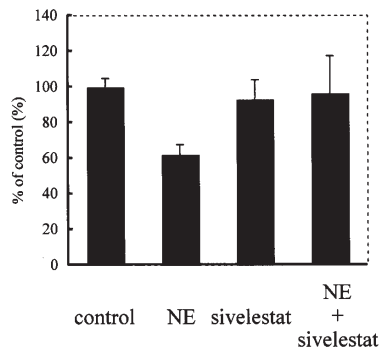

Figure 4. TGF- $\alpha$ secretion levels. TE-13 cells were grown to confluence. Cells were then treated for 10 min with NE $(5 \mu \mathrm{g} / \mathrm{ml})$ alone or together with sivelestat $(100 \mu \mathrm{g} / \mathrm{ml})$. The concentrations of TGF- $\alpha$ protein in aliquots of the cell culture supernatants (A) or the cell lysates (B) were measured by using a TGF- $\alpha$ ELISA kit. The values (mean \pm SD) were obtained from three separate experiments.

were measured by fluorescence detection. As shown in Fig. 3, $5 \mu \mathrm{g} / \mathrm{ml}$ of $\mathrm{NE}$ treatment increased the number of the cells through the membrane to $125 \%$ compared to number of the cells without NE treatment $(\mathrm{p}<0.01)$. Addition of $10 \mu \mathrm{g} / \mathrm{ml}$ sivelestat with $5 \mu \mathrm{g} / \mathrm{ml} \mathrm{NE}$ prevented migratory activity induced by NE in TE-13 cells. Furthermore, $500 \mu \mathrm{g} / \mathrm{ml}$ sivelestat inhibited NE-induced migration to $30.7 \%$ compared to cells with NE treatmenet alone $(\mathrm{p}<0.001)$.

Secretion of TGF-a. We have demonstrated the growth stimulatory effects of NE in esophageal cancer cells. However, the mechanism of the phenomenon remains unclear. In the analysis of normal airway epithelial cells, Kohri et al (6) reported that human NE cleaved and released from the cell membrane, and exerts its function by stimulating EGFR and signal transduction resulting in the mucinous secretion from the peripheral air way epithelial cells. To examine whether the stimulation of NE cleaves and releases TGF- $\alpha$ in esophageal carcinoma cells, the quantity of TGF- $\alpha$ in the supernatant or in the cell lysate was determined following treatment with $5 \mu \mathrm{g} / \mathrm{ml} \mathrm{NE}$ in TE-13 by ELISA. After treatment with $5 \mu \mathrm{g} / \mathrm{ml} \mathrm{NE}$ for $10 \mathrm{~min}$ in the serumstarved medium, the secreted TGF- $\alpha$ detected in the medium

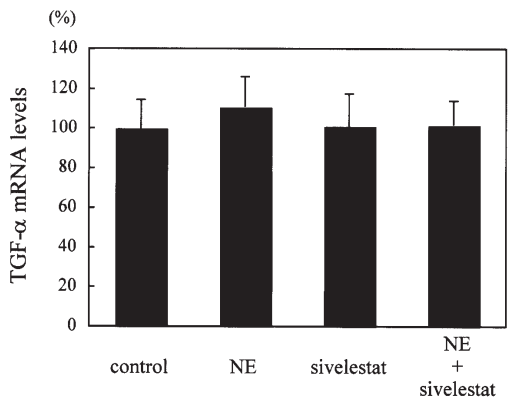

Figure 5. TGF- $\alpha$ mRNA expression levels. TE-13 cells were incubated with $5 \mu \mathrm{g} / \mathrm{ml} \mathrm{NE}$ alone or together with $100 \mu \mathrm{g} / \mathrm{ml}$ sivelestat for $10 \mathrm{~min}$. RNA was extracted from cells in the exponential growth phase, and mRNA levels were normalized against ACTB expression. The values (mean $\pm \mathrm{SD}$ ) were obtained from three separate experiments.

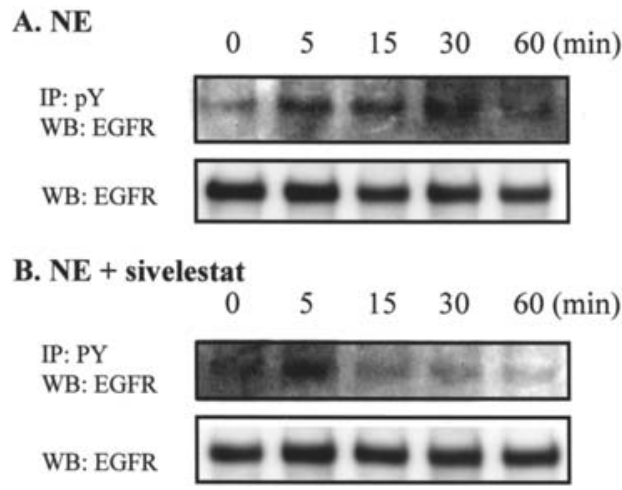

Figure 6. Neutrophil elastase (NE) transactivates EGFR and sivelestat inhibits NE-induced EGFR activation. TE-13 cells were treated for up to 60 min with $5 \mu \mathrm{g} / \mathrm{ml} \mathrm{NE}$ alone (A) or together with $100 \mu \mathrm{g} / \mathrm{ml}$ sivelestat (B). After lysis, EGFR was immunoprecipitated with anti-EGFR antibody and tyrosine-phosphorylated EGFR was detected by immunoblotting with anti-phosphotyrosine antibody. The total amount of EGFR in the immunoprecipitate was determined by reprobing the same blot with anti-EGFR antibody.

was increased to 1.53 -fold in the supernatant compared with that detected in serum-starved control cells $(4.82 \mathrm{pg} / \mathrm{ml}$ after stimulation with NE, $1.37 \mathrm{pg} / \mathrm{ml}$ in serum-starved cells, $\mathrm{p}<0.01)$ as shown in Fig. 4A. However, the concentration of TGF- $\alpha$ in the cell lysate was reduced in NE-treated TE-13 cells $(5.55 \mathrm{pg} / \mathrm{ml}, \mathrm{p}<0.01)$ compared with the control cells $(8.20 \mathrm{pg} / \mathrm{ml})$ as demonstrated in Fig. 4B. This result suggested that TGF- $\alpha$ was released and secreted from the cells to the supernatant after treatment of cells with NE. Moreover, we demonstrated that sivelestat alone does not affect the amount of TGF- $\alpha$ in the supernatant and the lysate. Furthermore, it was clearly shown that sivelestat completely inhibited the NE-induced release of TGF- $\alpha$ to the supernatant (Fig. 4A and B).

With regard to mRNA, semi-quantitative RT-PCR analysis was performed to examine the alteration of mRNA for TGF- $\alpha$. TE-13 cells were incubated with $5 \mu \mathrm{g} / \mathrm{ml} \mathrm{NE}$ either alone or in combination with $100 \mu \mathrm{g} / \mathrm{ml}$ sivelestat for $10 \mathrm{~min}$, and cells were harvested and mRNA was then isolated from the cells. There was no difference in the mRNA levels of TGF- $\alpha$ among the control, NE, sivelestat and NE/sivelestat combination 
A. NE

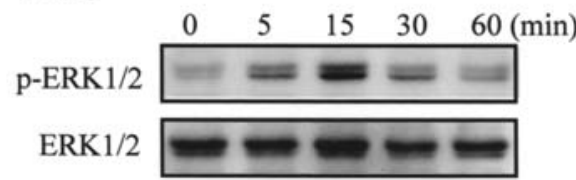

B. NE + sivelestat

$\begin{array}{lllll}0 & 5 & 15 & 30 & 60\end{array}(\mathrm{~min})$

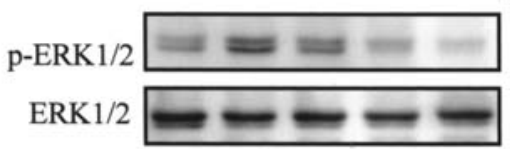

C.

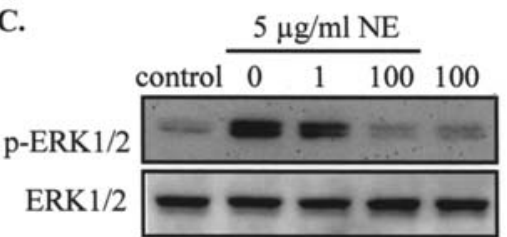

Figure 7. Sivelestat inactivates the mitogenic ERK1/2 signaling pathway in TE-13 cells. TE-13 cells were treated for up to $60 \mathrm{~min}$ with $5 \mu \mathrm{g} / \mathrm{ml} \mathrm{NE}$ alone (A) or together with $100 \mu \mathrm{g} / \mathrm{ml}$ sivelestat (B). After lysis, serinephosphorylated ERK1/2 was detected by immunoblotting with antiphosphorylated ERK1/2 antibody. The total amount of ERK1/2 in the lysis protein was determined by reprobing the same blot with anti-ERK $1 / 2$ antibody. Results are representative of three separate experiments. (C) Sivelestat inhibits NE-induced EGFR activation in a dose-dependent manner. Western blotting shows the dose-dependent protein phosphorylation levels of ERK1/2. TE-13 cells were grown to confluence, and incubated with $5 \mu \mathrm{g} / \mathrm{ml} \mathrm{NE}$ alone or together with 1 and $100 \mu \mathrm{g} / \mathrm{ml}$ sivelestat and $100 \mu \mathrm{g} / \mathrm{ml}$ sivelestat alone. Results are representative of three separate experiments.

treatment groups (Fig. 5), confirming that the process of these phenomena do not involve the mRNA levels.

Phosphorylation of EGFR and ERK cascade. In order to confirm that NE-induced cleavage of TGF- $\alpha$ activates the EGFR phosphorylation, we investigated the EGFR phosphorylation after TE-13 cells were treated with $\mathrm{NE}$ and/or sivelestat for $0,5,15,30$ and $60 \mathrm{~min}$. Initial increase of EGFR phosphorylation induced by treatment with $5 \mu \mathrm{g} / \mathrm{ml} \mathrm{NE}$ was observed at only 5 min of treatment with NE, and reached its maximal level (5.16 times compared to the control level) at 30 min as demonstrated in Fig. 6A. Total intracellular level of EGFR detected by Western blot was not affected by NE treatment.

To confirm that this increase of the EGFR phosphorylation can be reversed by the administration of sivelestat, the EGFR phosphorylation was observed when TE-13 cells were co-treated with $5 \mu \mathrm{g} / \mathrm{ml} \mathrm{NE}$ and $100 \mu \mathrm{g} / \mathrm{ml}$ sivelestat. As demonstrated in Fig. 6B, although the initial phophorylation of EGFR at 5 min was not affected by sivelestat, NE-induced phosphorylation of EGFR was significantly decreased after co-treatment with NE and sivelestat for 15, 30 and $60 \mathrm{~min}$, suggesting that sivelestat might prevent the signal transduction by inhibiting the release of TGF- $\alpha$ from the cell surface.

Furthermore, we investigated phosphorylation of the ERK cascade, downstream of EGFR. Initial increase of the ERK phosphorylation was induced by treatment with $5 \mu \mathrm{g} / \mathrm{ml} \mathrm{NE}$ at
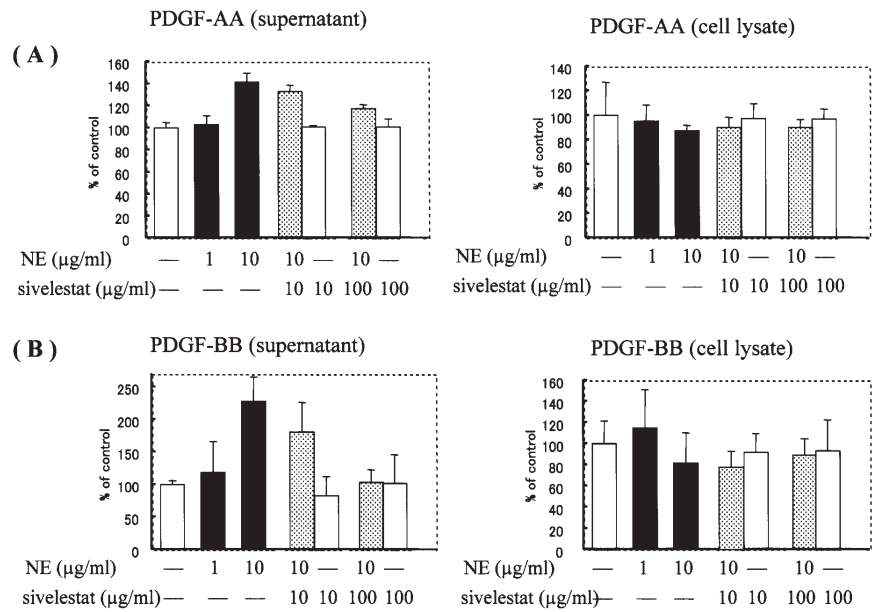

(C)
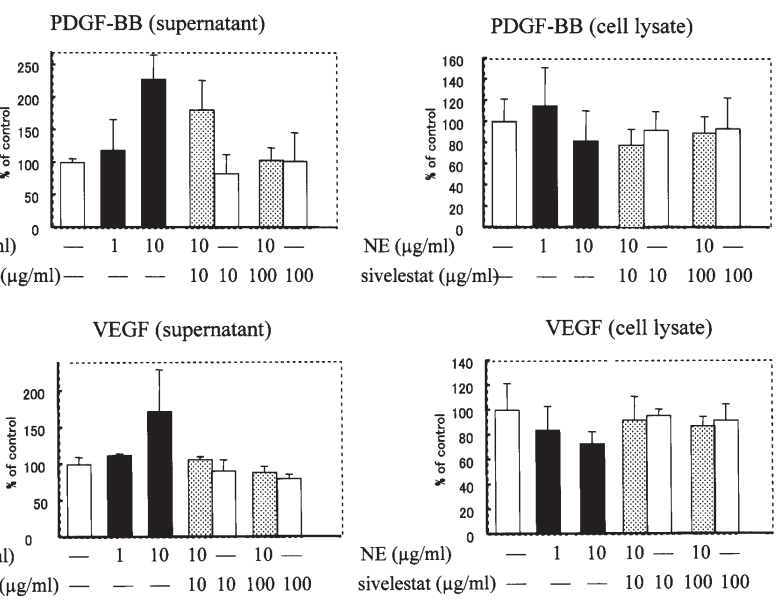

sivelestat $(\mu \mathrm{g} / \mathrm{ml})-\quad-1010100100$

Figure 8. Secretion levels of PDGF-AA, PDGF-BB and VEGF. TE-13 cells were grown to confluence. Cells were then treated for 10 min with NE $(5 \mu \mathrm{g} / \mathrm{ml})$ alone or together with sivelestat $(10$ or $100 \mu \mathrm{g} / \mathrm{ml})$. The concentrations of PDGF-AA (A), PDGF-BB (B) and VEGF (C) protein in aliquots of the cell lysates or the cell culture supernatants were measured by using a PDGF-AA, PDGF-BB and VEGF ELISA kit, respectively. The values (mean $\pm \mathrm{SD}$ ) were obtained from three separate experiments.

only $5 \mathrm{~min}$, reaching its maximal level at $15 \mathrm{~min}$ as shown in Fig. 7A; however, after treatment with $100 \mu \mathrm{g} / \mathrm{ml}$ sivelestat in combination with $5 \mu \mathrm{g} / \mathrm{ml} \mathrm{NE}$, sivelestat significantly inhibited the peak level of the ERK phosphorylation as clearly demonstrated in Fig. 7B. Moreover, the dose-dependent inhibition was examined. As shown in Fig. 7C, sivelestat inhibited the peak phosphrylation of ERK at 15 min by treatment with NE in a dose-dependent manner. Sivelestat $(100 \mu \mathrm{g} / \mathrm{ml})$ completely inhibited NE-induced ERK phosphorylation compared to the control level.

Secretion of PDGF and VEGF. We demonstrated previously that multiple growth factor-receptor systems are involved in the growth and progression of esophageal carcinoma cells $(15,16)$. PDGF and VEGF are also involved in these processes and these growth factors are also cleaved in the cell membrane by proteolytic enzymes as reported elsewhere $(17,18)$. We speculated that the NE cleaves and stimulate the secretion of these growth factors in the medium- like TGF- $\alpha$.

TE-13 cells were treated with NE and/or sivelestat at indicated concentration for $10 \mathrm{~min}$ and then cell culture supernatant was collected and cells were diluted with lysis buffer to collect the cell lysate. Secretions of PDGF-AA, PDGF-BB and VEGF were examined by ELISA. Although the stimulation of $1 \mu \mathrm{g} / \mathrm{ml} \mathrm{NE}$ did not significantly induce PDGF-AA, treatment with $10 \mu \mathrm{g} / \mathrm{ml}$ NE induced PDGF-AA levels in the cell culture supernatant to $141.9 \%(\mathrm{p}<0.01)$ compared to the control (Fig. 8A). On the other hand, PDGF$\mathrm{AA}$ in the cell lysate was decreased following stimulation 
with $10 \mu \mathrm{g} / \mathrm{ml}$ NE. This result suggested that PDGF-AA was secreted to the cell culture supernatant by stimulation of NE. NE-induced secretion of PDGF-AA was also reversed as shown in Fig. 8A. Sivelestat (10 and $100 \mu \mathrm{g} / \mathrm{ml})$ decreased PDGF-AA levels to 133.0 and $117.6 \%$, respectively, compared to the control in the cell culture supernatant. The effect of sivelestat inhibiting NE was dose-dependent.

The similar results were obtained in the secretion of the PDGF-BB (Fig. 8B) and VEGF (Fig. 8C). Secretion of PDGF$\mathrm{BB}$ to the cell culture supernatant was also increased to $227.7 \%$ ( $p<0.01)$ compared to the control following stimulation with $10 \mu \mathrm{g} / \mathrm{ml} \mathrm{NE}$. Sivelestat also inhibited the secretion of PDGF-BB in the supernatant and $100 \mu \mathrm{g} / \mathrm{ml}$ sivelestat completely inhibited the increased secretion of PDGF-BB by $10 \mu \mathrm{g} / \mathrm{ml} \mathrm{NE}(36.5 \%$ compared to $10 \mu \mathrm{g} / \mathrm{ml} \mathrm{NE}$ treatment, $\mathrm{p}<0.05)$. Moreover, we determined the secretary effect of NE to VEGF. NE $(10 \mu \mathrm{g} / \mathrm{ml})$ promoted the secretion of not only PDGF-AA and PDGF-BB but also VEGF to $171.6 \%$ compared to the control $(\mathrm{p}<0.05)$ (Fig. 8C). Sivelestat $(10$ and $100 \mu \mathrm{g} /$ $\mathrm{ml}$ ) inhibited $10 \mu \mathrm{g} / \mathrm{ml}$ NE-induced secretion of VEGF 106.1 and $88.4 \%$ compared to the control, respectively.

\section{Discussion}

We previously demonstrated that esophageal carcinoma cells have multi-autocrine loops for the development of growth and metastatic potential. Among these growth factors, EGF and TGF- $\alpha$ play prominent roles through EGFR, which is activated by phosphorylation of tyrosine residues. The activated receptor mediates the growth signal through the ras-raf-mitogen-activated protein (MAP)/extracellular signalregulated kinase (ERK) kinase MAPK pathway $(19,20)$. Activation of this pathway leads to phosphorylation of two MAPKs, ERK-1 (p44MAPK) and ERK-2 (p42MAPK), which translocate to the nucleus to regulate gene transcription necessary for mitogenesis, including G1 cyclines. Moreover, EGF and TGF- $\alpha$ induce not only the expression of their own receptor but also the expression of other autocrine growth factor-receptor systems including PDGF, VEGF, insulin-like growth factor, ERBB2 and matrix metalloproteinases which degrade extracellular conformation for cancer cells to invade and metastasize to other organs $(15,16,21-24)$.

In the present study, we clearly demonstrated that the inflammatory regulation is closely related to the progression of esophageal carcinomas. Firstly, the growth and invasion activity of esophageal carcinoma cells are stimulated by NE which is released from the activated neutrophils. Secondly, the growth stimulation occurs via the cleaved TGF- $\alpha$ from the cell membrane, which activates the EGFR and then the subsequent intracellular signal transduction. Thirdly, NE stimulates the release of several growth factors including PDGFs and VEGF that are closely related to the growth and angiogenesis of tumor cells. Finally, sivelestat, a specific inhibitor of NE, can inhibit the NE-induced stimulation of the esophageal cancer cells.

A considerable amount of NE is released from activated neutrophils which are induced by systemic cytokines including TNF- $\alpha$, IL- 8 and IL- 6 produced by macrophages in the lung $(25,26)$. This systemic inflammatory response syndrome (SIRS) is often observed after surgical injury like esophagectomy, which influences on the function of leukocytes and endothelial cells leading to the acute respiratory distress syndrome (ARDS) or acute lung injury (ALI) with the destruction of the alveolar construction of the lung. NE mediates both direct tissue damage and the upregulation of pro-inflammatory cytokines such as interleukin-8 (27), and it has also been demonstrated that NE impairs apoptotic cell recognition by cleaving the phosphatidylserine receptor and CD14 (28-30). Surgical stress promotes inflammation and suppresses apoptotic cell recognition of host factors. Considering these perioperative and oncological circumstances, it is quite reasonable to argue that the occult carcinoma cells in the focal area or the circulating blood systems, acquire the capacity to regrow and spread rapidly after surgery.

NE has been reported to cleave TGF- $\alpha$ precursor that are located on the cell surface (31), resulting in the release of mature TGF- $\alpha$ in fibroblasts (32) and human airway epithelial cells (6), however, it has not been demonstrated in esophageal carcinomas so far. As shown in the present study, the EGFR tyrosine phosphorylation occurred as early as $5 \mathrm{~min}$ and it reached the maximal level at $30 \mathrm{~min}$ by $\mathrm{NE}$ stimulation in TE-13 cells caused by the release of TGF- $\alpha$ which functions in an autocrine manner. Addition of a specific NE inhibitor sivelestat with NE highly suppressed the EGFR tyrosine phosphorylation at maximal level and this inhibition effect was maintained during the stimulation period with NE. Moreover, we demonstrated that sivelestat significantly suppressed the activation of the MAPK trans-duction, suggesting that inhibition of NE can be one of the molecular target for the treatment of cancer progression.

The other findings in the present study show that NE induced other growth factors including PDGFs and VEGF from the cell surface of esophageal carcinoma cells like TGF- $\alpha$ and that the release of these growth factors were completely abolished by the concomitant administration with $100 \mu \mathrm{g} / \mathrm{ml}$ sivelestat. The activation of the MAPK signal transduction is also mediated via PDGFs (33) and VEGF (34). As we have shown, NE-induced activation of these signal transduction might also involve the activation of these growth factor receptor systems (35). As induction of VEGF initiates the formation of new blood vessels, PDGFs might be involved in the maintenance of these vessels as well as stimulation of the proliferation of tumor cells (36-39). Although it can not be concluded which growth factors have major roles in the growth promotion and migratory ability in TE-13 cells, NE might have potential to activate other growth factor-receptor systems in vivo. As it was reported that NE-like enzymes cleave and release TGF- $\alpha(40,41)$, NE-like enzymes from cancer cells might also be involved in the progression of esophageal carcinomas, which should be elucidated in further studies. The higher concentration of sivelestat $>500 \mu \mathrm{g} / \mathrm{ml}$ inhibited the growth of carcinoma cells further than was expected. The mechanism of the growth suppression of sivelestat is not fully understood; however, these results strongly indicate that the administration of the agent might be useful in preventing not only surgical complications including ARDS but also the rapid progression of occult cancer cells by inhibiting the release of growth factors from esophageal carcinoma cells. 


\section{References}

1. Werb Z and Gordon S: Elastase secretion by stimulated macrophages: characterization and regulation. J Exp Med 142: 361-377, 1975 .

2. Janoff A and Schere J: Mediators of inflammation in leukocyte lysosomes, IX. Elastolytic activity in granules of human polymorphonuclear leukocytes. J Exp Med 128: 1137-1156, 1968.

3. Janoff A: Elastase in tissue injury. Annu Rev Med 36: 207-216, 1985.

4. Mainardi C, Dixit S and Kang A: Degradation of type IV (basement membrane) collagen by a proteinase isolated from human polymorphonuclear leukocyte granules. J Biol Chem 255: 5435-5441, 1980 .

5. McDonald JA and Kelley DG: Degradation of fibronectin by human leukocyte elastase: release of biologically active fragments. J Bio Chem 255: 8848-8858, 1980.

6. Kohri K, Ueki FI and Nadel AJ: Neutrophil elastase induces mucin production by ligand-dependent epidermal growth factor receptor activation. Am J Physiol Lung Cell Mol Physiol 283: 531-540, 2002.

7. Yamashita J, Ogawa M, Ikei S, et al: Production of immunoreactive polymorphonuclear leukocyte elastase in human breast cancers: possible role of polymorphonuclear leukocyte elastase in the progression of human breast cancer. Br J Cancer 69: 72-76, 1995.

8. Yamashita J, Tashiro K, Toneda S, Kawahara K and Shirasaka T: Local increase in polymorphonuclear leukocyte elastase is associated with tumor invasiveness in non-small lung cancer. Chest 109: 1328-1334, 1996.

9. Yamashita J, Ogawa M, Abe M, et al: Tumor neutrophil elastase is closely associated with the direct extension of non-small cell lung cancer into the aorta. Chest 111: 885-890, 1997.

10. Kamohara H, Sakamoto K, Mita S, An XY and Ogawa M: Neutrophil elastase inhibitor (ONO-5046. Na) suppresses the proliferation, motility and chemotaxis of a pancreatic carcinoma cell line, Capan-1. Res Commun Mol Pathol Pharmacol 98: 103-108, 1997.

11. Inada M, Yamashita J, Nakano S and Ogawa M: Complete inhibition of spontaneous pulmonary metastasis of human lung carcinoma cell line EBC-1 by a neutrophil elastase inhibitor (ONO-5046-Na). Anticancer Res 18: 885-890, 1998.

12. Mossman T: Rapid colorimetric assay for cellular growth and survival: application to proliferation and cytotoxicity assays. J Immunol Methods 65: 55-63, 1983.

13. Gildea JJ, Harding MA, Gulding KM and Theodorescu D: Transmembrane motility assay of transiently transfected cells by fluorescent cell counting and luciferase measurement. Biotechniques 29: 81-86, 2000.

14. Wada Y, Yoshida K, Suzuki T, et al: Synergistic effects of docetacel and S-1 by modulating the expression of metabolic enzymes of 5-fluorouracil in human gastric cancer cell lines. Int $\mathrm{J}$ Cancer (In press).

15. Yoshida K, Kuniyasu H, Toge T, Yasui W, Kitadai Y and Tahara E: Expression of growth factors and their receptors in human esophageal carcinomas; regulation of expression by epidermal growth factor and transforming growth factor-alpha. J Cancer Res Clin Oncol 119: 401-407, 1993.

16. Yoshida K, Yasui W, Ito $\mathrm{H}$ and Tahara E: Growth factors in progression of human esophageal and gastric carcinomas. Exp Pathol 40: 291-300, 1991.

17. Plouet J, Moro F, Bertagnolli S, et al: Extracellular cleavage of the vascular endothelial growth factor 189-amino acid formed by urokinase is required for its mitogenic effect. J Biol Chem 272: 13390-13396, 1997.

18. Siegfried G, Basak A, Prichett-Pejic W, et al: Regulation of the stepwise proteolytic cleavage and secretion of PDGF-B by the proprotein convertases. Oncogene 24: 6925-6935, 2005.

19. Davis RJ: The mitogen-activated protein kinase signal transduction pathway. J Biol Chem 268: 14553-14556, 1993.

20. Denhardt DT: Signal-transducting protein phosphorylation cascades mediated by Ras/Rho proteins in the mammalian cell: the potential for multiplex signaling. Biochem J 318: 729-747, 1996.
21. Coffey RJ Jr, Derynck R, Wilcox JN, et al: Production and autoinduction of transforming growth factor- $\alpha$ in human keratinocytes. Nature 328: 817-820, 1987.

22. Yoshida K, Kyo E, Tsuda T, et al: EGF and TGF-alpha, the ligands of hyperproduced EGFR in human esophageal carcinomas, act as autocrine growth factors. Int J Cancer 45: $131-135,1990$.

23. Yoshida K, Tsujino T, Yasui W, et al: Induction of growth factor receptor and metalloproteinase genes by epidermal growth factor and/or transforming growth factor alpha in human gastric carcinoma cell line MKN-28. Jpn J Cancer Res 81: 793-798, 1990.

24. Awwad RA, Sergina N, Yang H, et al: The role of transforming growth factor $\alpha$ in determining growth factor independence. Cancer Res 63: 4371-4378, 2003.

25. Sato N, Murakami K, Ishida K, Ikeda K and Saito K: Pulmonary hypertension and polymorphonuclear leukocyte elastase after esophageal cancer operation. Ann Thorac Surg 51: 754-758, 1991

26. Sakamoto K, Arakawa H, Mita S, et al: Elevation of circulating interleukin-6 after surgery. Cytokine 6: 181-186, 1994.

27. Walsh DE, Greene CM, Carroll TP, et al: Interleukin-8 upregulation by neutrophil elastase is mediated by MyD88/IRAK/ TRAF-6 in human bronchial epithelium. J Biol Chem 276: 35494-35499, 2001

28. Devitt A, Moffatt OD, Raykundalia C, Capra JD, Simmons DK and Gregory CD: Human CD14 mediates recognition and phagocytosis of apoptotic cells. Nature 392: 505-509, 1998.

29. Vandivier RW, Fadok VA, Hoffmann PR, et al: Elastasemediated phosphatidylserine receptor cleavage impairs apoptotic cell clearance in cystic fibrosis and bronchiectasis. J Clin Invest 109: 661-670, 2002.

30. Henriksen PA, Devitt A, Kotelevtsev Y and Sallenave JM: Gene delivery of the elastase inhibitor elafin protects macrophages from neutrophil elastase-mediated impairment of apoptotic cell recognition. FEBS Lett 574: 80-84, 2004

31. Lee DC, Fenton SE, Berkowits EA, et al: Transforming growth factor $\alpha$ : expression, regulation, and biological activities. Pharmacol Rev 47: 51-85, 1995.

32. Mueller SG, Paterson AJ and Kudlow JE: Transforming growth factor $\alpha$ in arterioles: cell surface processing of its precursor by elastases. Mol Cell Biol 10: 4596-4602, 1990

33. Finlay GA, Thannickal VJ, Fanburg BL and Kwiatkowski DJ: Platelet-derived growth factor-induced p42/44 mitogen-activated protein kinase activation and cellular growth is mediated by reactive oxygen species in the absence of TSC2/tuberin. Cancer Res 65: 10881-10890, 2005.

34. Wong C and Jin ZG: Protein kinase C-dependent protein kinase D activation modulates ERK signal pathway and endothelial cell proliferation by vascular endothelial growth factor. J Biol Chem 280: 33262-33269, 2005

35. Robert MS, Jung SH, Gail LG and Thomas FD: Dissociation of the chemotactic and mitogenic activities of platelet-derived growth factor by human neutrophil elastase. J Cell Biol 100: 351-356, 1985 .

36. Folkman $\mathrm{J}$ : the role of angiogenesis in tumor growth. Semin Cancer Biol 3: 65-71, 1992

37. Kolch W, Martiny-Baron F, Kieser A and Marme D: Regulation of the expression of the VEGF/VPS and its receptors: role in tumor angiogenesis. Breast Cancer Res Treat 36: 139-155, 1995.

38. Dvorak HF: Vascular permeability factor/vascular endothelial growth factor: a critical cytokine in tumor angiogenesis and a potential target for diagnosis and therapy. J Clin Oncol 20: 4368-4380, 2002

39. Bergers G, Song S, Meyer-Morse N, Bergsland E and Hanahan D: Benefits of targeting both pericytes and endothelial cells in the tumor vasculature with kinase inhibitors. J Clin Invest 111: 1287-1295, 2003.

40. Cappelluti E, Strom SC and Harris RB: Potential role of two novel elastase-like enzymes in processing pro-transforming growth factor- $\alpha$. Biochemistry 32: 551-560, 1993.

41. Teixido J, Wong ST, Lee DC and Massague J: Generation of transforming growth factor- $\alpha$ from the cell surface by an Oglycosylation-independent multistep process. J Biol Chem 265 : 6410-6415, 1990 . 